\title{
Gas: Source of prosperity
}

\section{Ms. A. Jorritsma-Lebbink}

Minister of Economic Affairs (opening address)

The Slochteren gas field has not only made a great contribution to the prosperity of The Netherlands, but it has also led to changes to this country in the socioeconomic sense. In a comparatively short time natural gas became the main fuel for our energy supply. That meant a major switch in manufacturing industry, public utilities and households.

On hearing the term 'natural gas', the average Dutch person immediately thinks of Slochteren. However, even so, Slochteren is far from being the sole source of Dutch gas. Quite a long time ago the government decided to develop the smaller fields with priority. This gave the Groningen field the role of 'balancing field', to be conserved for as long as possible for future use. That was a wise decision.

It was also a wise move to apply the gas revenues for broader purposes than social improvements alone. We have used those revenues in order to consolidate our eco-

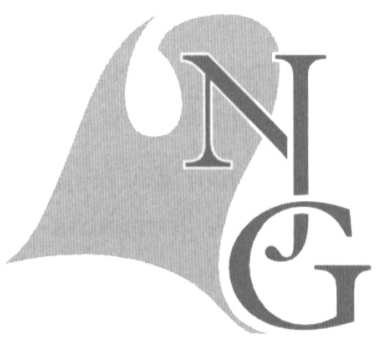

nomic and infrastructural base as well. We are already enjoying the resultant benefits today, and we shall continue to enjoy them in the future.

Since its setting-up in 1962, Gasunie has played a great and pivotal role in the Dutch natural gas supply. Moreover, that role is far from being played out yet. New challenges lie ahead of you. Step by step, the gas industry is being liberalized. Thanks to the European Union the gas trade has gained a European dimension. We see a complex network of trans-European pipelines being built.

Together, we - Gasunie, other market players and government - must respond effectively to those new developments. Then Dutch natural gas production and trade will remain what they have always been: a source of prosperity and sustainable economic development. 